\title{
(อ) OPEN ACCESS \\ How should the 'privilege' in therapeutic privilege be conceived when considering the decision-making process for patients with borderline capacity?
}

\author{
Sumytra Menon $\odot,{ }^{1}$ Vikki Entwistle, ${ }^{2}$ Alastair Vincent Campbell, ${ }^{2}$ \\ Johannes J M van Delden ${ }^{3}$
}

${ }^{1}$ Centre for Biomedical

Ethics, National University of Singapore, Singapore

${ }^{2}$ Centre for Biomedical Ethics, National University of Singapore, Singapore ${ }^{3}$ Julius Center for Health Sciences, University Medical Center, Utrecht, The Netherlands

Correspondence to Dr Sumytra Menon, National University of Singapore, Singapore 117597, Singapore; sumy.menon@nus.edu.sg

Received 27 August 2019 Revised 30 November 2019 Accepted 2 December 2019 Published Online First 7 January 2020

\section{Check for updates}

(C) Author(s) (or their employer(s)) 2021. Re-use permitted under CC BY-NC. No commercial re-use. See rights and permissions. Published by BMJ.

To cite: Menon $\mathrm{S}$, Entwistle V, Campbell AV, et al. J Med Ethics 2021;47:47-50.

\section{ABSTRACT}

Therapeutic privilege (TP) is a defence that may be available to doctors who fail to disclose to the patient relevant information when seeking informed consent for treatment if they have a reasonable belief that providing that information would likely cause the patient concerned serious physical or mental harm. In a landmark judgement, the Singapore Court of Appeal introduced a novel interpretation of TP, identifying circumstances in which it might be used with patients who did not strictly lack capacity but might be inclined to refuse recommended treatments. In this paper, we explore the conceptual and practical challenges of this novel interpretation of TP. We propose that more emphasis should be placed on forms of shared and supported decision-making that foster the autonomy of patients with compromised mental capacity while being mindful of the need to safeguard their well-being. The kind of privilege that doctors might need to invoke is one of time and supportive expertise to ensure a flexible, responsive approach calibrated to the individual patients needs. The provision of such service would extinguish the need for the novel TP proposed by the Singapore Court of Appeal.

\section{INTRODUCTION}

Doctors can struggle with their duty to safeguard and protect patients while simultaneously respecting their decisions especially when patients have borderline capacity. They may justifiably be uncertain whether, how and/or to what extent they may offer decisional support and protection because this might be perceived as an unnecessary intervention in the individual's rights. ${ }^{1}$

In most jurisdictions, individuals with mental capacity have the legal authority to make their own healthcare decisions, at least about whether or not to accept clinically recommended treatments, although this may not extend to requesting treatment that doctors judge clinically inappropriate. For individuals who lack capacity to make a specific healthcare decision, others are usually empowered through legal mechanisms to make it on their behalf. The binary distinction between having and lacking mental capacity labels and categorises individuals in ways that are not always helpful. It ignores the murkier middle ground where someone's capacity may hover just above or just below the borderline, wherever it is drawn.

The unhelpfulness of the binary distinction was recently highlighted in a Singapore Court of Appeal case where the court introduced a novel interpretation of therapeutic privilege (novel TP). ${ }^{2}$ While the court attempted to limit the use of novel TP to exceptional cases involving people with borderline capacity, we find its development and the implications for healthcare practice and patients troubling.

In this paper, we will focus on patients who have mental capacity but are around the borderline, for example, because of fluctuating capacity. These patients may have limited insight into the implications of treatment opinions and may be at risk of making decisions that many would consider contrary to their best interests and reflecting insufficient understanding. We will refer to this group as individuals with compromised capacity. Capacity may be compromised for neurological and/or social reasons, such as lower levels of education or literacy. We will explore the conceptual and practical challenges of novel TP, introduced by the Singapore Court of Appeal, and propose an alternative approach to novel TP. In this paper, we argue that the 'privilege' in TP with respect to individuals with compromised capacity should be interpreted as the privilege to take time and where necessary involve additional support to engage in meaningful interactions with them to ascertain and then seek to provide appropriately flexible support to foster their autonomy with respect to healthcare decisionmaking while being mindful of a need to safeguard their well-being.

\section{MENTAL CAPACITY FRAMEWORKS AND LEGAL CAPACITY}

In order to frame our discussion, we briefly outline two major legal frameworks for mental capacity, and then a recent proposal advanced by the United Nations Committee on the Rights of Persons with Disabilities (CPRD). Both legal frameworks produce a binary outcome where an individual either has capacity or lacks capacity to make a specific decision. The first framework is the functional test, where the individual's ability to make the specific decision is assessed to determine mental capacity. The second framework is a two-stage test, where an individual lacks mental capacity if their inability to decide (functional stage of the test) is caused by an impairment or a disorder of the functioning of the mind or brain (clinical stage of the test).

These frameworks have been challenged by the CPRD proposal as flawed because they presume "to be able to accurately assess the inner-workings of 
the human mind, and when the person does not pass the assessment, then denies him or her a core human right - the right to equal recognition before the law." ${ }^{3}$ Instead, the CPRD advances the concept of "universal legal capacity" so that "all persons regardless of disability or decision-making abilities, inherently possess legal capacity" and "requires that support be provided in the exercise of legal capacity". ${ }^{3}$ In the CPRD proposal, there is no borderline on the capacity spectrum and a supported, rather than substituted paradigm is proposed for decision-making. ${ }^{3} \mathrm{We}$ will use these frameworks and the CPRD proposal to provide the background for healthcare decision-making and for evaluating TP, which is what we will turn our attention to next.

\section{A NOVEL INTERPRETATION OF TP}

TP is accepted in many jurisdictions, including England and Wales, Netherlands, Australia and Canada, as an exception to the rule requiring the doctor to provide relevant information about treatments to competent patients as part of the consent process. The commonly accepted understanding of TP, as a privilege of withholding information, is that it is exercised by the doctor who reasonably believes that providing the relevant information to a particular patient would cause him/her serious physical or mental harm. ${ }^{24}$ There are very few reported cases where TP has been accepted as a defence for failing to disclose relevant information to a patient when seeking informed consent for treatment (see for example Tai $v$ Saxon where the doctor exercised TP and did not disclose to the patient a remote risk of perforation and fistula from a hysterectomy because she was very anxious and to do so would worsen her anxiety). ${ }^{5}$ It may therefore be more accurately described as therapeutic exception, rather than TP, and this is indeed the terminology adopted in some jurisdictions.

In constructing novel TP, the Singapore court extended the scope of the exception to provide relevant information to a patient. The court commented that novel TP could be exercised on patients who "though not strictly lacking mental capacity, nonetheless suffered from such an impairment of his decisionmaking abilities that the doctor would be entitled to withhold the information" if certain conditions were met. ${ }^{2}$ The three conditions are "(a) the benefit of the treatment to the patient, (b) the relatively low risk presented and (c) the probability that even with suitable assistance the patient would likely refuse such treatment owing to some misapprehension of the information stemming from the impairment". The court gave an example of "certain geriatric patients" who may be "easily frightened out of having even relatively safe treatments that can drastically improve their quality of life, and whose state of mind, intellectual abilities or education may make it impossible or extremely difficult to explain the true reality to them". ${ }^{2}$

The rationale for this development may have been due to the binary capacity test in the Singapore Mental Capacity Act. So, the Singapore court may be trying to offer doctors a means to protect individuals with compromised capacity via TP since these individuals technically have capacity and therefore should be able to protect themselves but yet appear to be at risk of making decisions that the doctors think are contrary to their best interests. Whatever the rationale, the development of novel TP is troubling for a number of reasons.

First, doctors are expected to weigh up the probability of informational and other decisional assistance failing before deciding whether to withhold it from a patient. This suggests that doctors need not even try to provide such assistance if they predict it is unlikely to work. It is hard to see how this course of action strikes the right balance between protection and respect for the individual because the outcome is entirely dependent on how the particular doctor interpreted the situation in determining whether to withhold the information or not. Furthermore, it is contrary to the principle in the Mental Capacity Act of Singapore (similar to that of England and Wales), that "a person is not to be treated as unable to make a decision unless all practicable steps to help him to do so have been taken without success". ${ }^{67}$

Second, it seems that the 'danger' in providing the patient with the information is that the patient might misapprehend it and refuse a treatment that the doctors perceive is low risk and beneficial because they are misapprehending the information. And therefore, the harm that the doctors would be attempting to avoid is the patient foregoing the treatment. However, the patient might not consider foregoing the treatment as harmful. If that is due to a lack of understanding, suitable assistance could potentially support and enhance the patient's ability to decide rather than nullifying it entirely.

Third, it seems prima facie counterintuitive and inconsistent that an individual who does not strictly lack mental capacity (judged by the two-stage functional and clinical test) could yet for reasons of state of mind, intellectual ability or education be able to understand sufficiently to make the decision. Here, however, the court is perhaps trying to reflect complex real-world ambiguities and concerns that binary tests of capacity neglect and that many health professionals will recognise. There is plenty of evidence to show that people with less education and/or literacy difficulties experience challenges working through the healthcare systems, engaging with healthcare professionals, and understanding health information. ${ }^{8}$ More generally, many people may have difficulty understanding health information, especially since medical care has become more complex and driven by technological advancements. Thus, although the court stressed that novel TP should only be applied in exceptional cases, there could be a large number of people whose decisional abilities are impaired. Rather than withhold information and exclude them from decision-making, it seems important to consider directing more resources (including consultation time) to support them, perhaps with a particular emphasis on the needs of those with more limited education, health literacy or sociocultural capital.

Although we dispute novel TP as the solution, the problem of compromised capacity and ambiguities of decisional competence that the Singapore court highlighted does need to be taken seriously. In the following section, we will consider shared and supported decision-making as alternatives to novel TP for individuals with compromised capacity.

\section{ALTERNATIVE APPROACHES TO NOVEL TP: SHARED AND SUPPORTED DECISION-MAKING}

Shared decision-making (SDM) is a collaborative process that attempts to straddle the middle ground between the doctor deciding what is best for patients, and the patient deciding based on options presented by the doctor. ${ }^{9-11}$ It has been variously defined and described but is usually understood to involve explicit consideration of patient values/preferences for several different treatment options. ${ }^{12}$

A distinction has been made between narrower and broader conceptions of SDM. ${ }^{13}$ Narrower conceptions emphasise the elicitation of patients' preferences or choices in ways that discourage professional 'interference' with these. They tend to assume choice-based models of autonomy that tend to idealise independence and reflect rather individualistic views of human beings. They are also oriented in part to protect patients from 
professional conflicts of interest or undue imposition of professional values. Broader conceptions of SDM typically build from a relational framing that acknowledges the critical role that others, including healthcare professionals, can have in fostering the patient's autonomy. ${ }^{11}$ They put more emphasis on the ways in which healthcare professionals can support patient involvement in decision-making processes and can accommodate respectful and constructive checking of the basis of patients' expressed preferences in the context of particular decisions and the alignment of these preferences with their deeper values and broader goals. Broader conceptions of SDM seem to have particular advantages for individuals with compromised capacity because they can incorporate well-calibrated support for the development of understanding and the checking and if necessary further consideration of preferences. ${ }^{11}$

SDM even in its broader forms is not a panacea and there are challenges to doing it well. Short consultation times and a lack of continuity of care can work against patient involvement in decision-making processes, and in less than highly skilful or virtuous hands, broader versions of SDM might seem to sanction a problematic imposition of professional views. ${ }^{13-15}$

Supported decision-making (SUDM) evolved as an approach for enhancing the rights of people with intellectual disabilities, with an emphasis on supporting the patient to decide, and rejecting the substitute and best interests decision-making paradigms. ${ }^{16}$ The Office of the High Commissioner for Human Rights defines SUDM as "the process whereby a person with a disability is enabled to make and communicate decisions with respect to personal or legal matters". ${ }^{17}$

SUDM is an approach rather than a model, and can encompass a wide range of 'supports' including advance care planning (ACP), and nominated healthcare decision-making proxies, which enable the patient's wishes to be honoured and carried out by others. Broader conceptions of SDM could perhaps include SUDM and be synergistic with ACP. The intention is that all individuals will be supported to make a decision, and their views respected regardless of whether they have or lack capacity to make the specific decision. However, SUDM has its challenges, and a fundamental concern is about patients who lack mental capacity and are unable to make decisions. In these cases, permitting the patient to make a decision 'with support' could be perceived as a decision taken for the patient by the individual providing the support because the patient lacked capacity to make the decision. ${ }^{18}$

Depending on the specific vulnerabilities of the individual with compromised capacity, it may not always be the case that he or she will be able to engage in SDM. Healthcare professionals may wish to engage in a combination of SUDM and SDM depending on the needs and circumstances of the patient. Broader conceptions of SDM and SUDM are also to some extent aligned with the Montgomery and Hii Chii Kok court decisions, which promote an approach that requires doctors to provide patients with information and advice that is tailored to the patient's needs and preferences, and to avoid dumping information which will be challenging for anyone to fully understand. ${ }^{24}$

Broader conceptions of SDM eschew a transactional model of exchanges of information and preferences. They can pay more attention to patients' decision-making capacity which they treat as relational and look for professional support to be calibrated to enhance. Within these conceptions, the behaviours of healthcare professionals that may seem at first blush to be inconsequential, such as being encouraging rather than being impatient with the patient, and taking time to make the patient comfortable during

\section{Box 1 Mr Low's case}

A team of healthcare professionals are caring for 68 -year-old $\mathrm{Mr}$ Low, who has early dementia but has capacity to decide on cataract surgery. Mr Low is a retired bus driver. He left school at the age of 11 to work as a gardener with his father. The doctors think he would likely benefit from cataract surgery, which they have assessed as low risk and highly beneficial because it will improve his eyesight and therefore his quality of life. They realise from Mr Low's records that he is afraid of surgery, and has a history of declining surgical interventions that they perceive are in his best interests. They learn that Mr Low is afraid of surgery because something went wrong during his aunt's surgery 20 years ago, and she died during the procedure. The healthcare professionals attempt to address his concerns and communicated clarifications using non-medical language.

Instead of applying novel TP and withholding their recommendation of cataract surgery, the doctors could inform Mr Low that there is a procedure that will likely restore his sight. They could offer to arrange a meeting for him with other patients in a similar situation, and from a similar background, who have undergone the procedure. They could encourage Mr Low to ask those patients questions about the procedure, and discuss any concerns he may have. In addition, the healthcare professionals explain in non-medical jargon the surgical aspects of the procedure. If feasible, support may be sought from Mr Low's loved ones and caregivers, to encourage him to learn more about the procedure, and to support him to make a decision, without applying any pressure. If Mr Low struggles with formulating such questions, then the healthcare professionals or Mr Low's loved ones could act as facilitators to start the conversation, or they may work together to develop a list of questions to ask his fellow patients. Other options that could be considered include a visit to the room where the procedure would take place, chatting to the healthcare professionals who work there, and seeing patients exiting the room after the procedure may have the desired effect of demystifying the procedure and reducing his fear. If and when he is more comfortable with the procedure, more relevant information about the surgery could be offered to him in a supportive and facilitative environment, and done so at a pace and manner that is conducive to Mr Low's particular needs. Mr Low may subsequently decide to undergo cataract surgery. However, he may also decline it even after the above support has been provided. If he declines, then this is a decision the healthcare professionals should respect, even if they believe it is not in his best interests.

the consultation can be seen as important to foster and enhance the patient's autonomy. ${ }^{11} 13$

The Singapore court stressed that TP was not applicable when patients were capable of making a choice and their doctor simply considered the choice was not in the patient's best interests. $^{2}$ When caring for someone with compromised capacity, the doctors will probably have a sense from their conversations with them and/or with others who know them well, that they may have difficulties with making a choice. Rather than withholding the information using novel TP, the doctors could usefully take steps to engage in flexibly responsive and creative communicative approaches oriented to support and enable patients to make, influence and otherwise be involved in decisions that affect them, in ways that foster, as far as possible, their capabilities and broader aspects of their well-being to increase the likelihood of them making a choice (see Mr Low's case in box 1). ${ }^{19}$ And if 
despite these efforts the patient still declines the treatment, then he or she is entitled to do so as a competent adult, even if the doctor thinks that the treatment is low risk, highly beneficial and in the patient's best interests.

\section{CONCLUSION}

Between the proverbial rock and a hard place, the privilege doctors should exercise (and be enabled by healthcare systems to exercise) when caring for individuals with compromised capacity is to offer a therapeutic service that is responsive, flexible and calibrated to the individual patient's needs. It should involve the individual with compromised capacity, their supportive loved ones and other community members as appropriate, to foster the autonomy of and to support the individual in question throughout the decision-making process. This may be achieved through SDM broadly conceived and/or SUDM, although its practical application in the healthcare system may be challenging. Indeed, SDM/SUDM can be calibrated for wider application to benefit all patients. Both approaches also resonate with the CPRD framework, which promotes universal legal capacity. Novel TP in the form proposed by the Singapore court should not be used even as a last resort in exceptional cases where the individual has borderline capacity to decide. Individuals who are truly incapable of making a choice lack mental capacity to make the specific decision, and to the extent that it is possible, they should be encouraged to be involved in the decision-making process, which should be taken by the relevant decision-maker and focused on the individual's best interests.

Contributors The paper was conceived by SM, JJMvD and VE. SM drafted the first manuscript. SM, JJMvD, VE and AVC made substantial contributions to the content, arguments and organisation of the paper, and revised it critically. All authors have read and approved the final manuscript.

Funding $S M, J J M v D$ and VE were in receipt of salaries from their respective universities.

Competing interests None declared.

Patient consent for publication Not required.

Provenance and peer review Not commissioned; externally peer reviewed.

Data availability statement There are no data in this work

Open access This is an open access article distributed in accordance with the Creative Commons Attribution Non Commercial (CC BY-NC 4.0) license, which permits others to distribute, remix, adapt, build upon this work non-commercially, and license their derivative works on different terms, provided the original work is properly cited, appropriate credit is given, any changes made indicated, and the use is non-commercial. See: http://creativecommons.org/licenses/by-nc/4.0/.

ORCID iD

Sumytra Menon http://orcid.org/0000-0001-9129-4072

\section{REFERENCES}

1 House of Lords select Committee on the mental capacity act. Report of session 2013-14: mental capacity act 2005: Post-legislative scrutiny. HL paper 139. Available: https://publications.parliament.uk/pa/ld201314/Idselect/ldmentalcap/139/139.pdf [Accessed 29 May 2019].

2 Hii Chii Kok v London Lucien Ooi, [2017] SGCA 38.

3 United Nations Committee on the Rights of Persons with Disabilities. General Comment No. 1: article 12: equality before the law. eleventh session, 2014. Available: https://documents-dds-ny.un.org/doc/UNDOC/GEN/G14/031/20/PDF/G1403120.pdf? OpenElement [Accessed 29 May 2019].

4 Montgomery v Lanarkshire Health Board, [2015] 1 AC 1430.

5 Tai v Saxon [1996] No 23/95, Western Australian Supreme Court (unreported).

6 Act MC, 177A C. Mental Capacity Act, Cap. 177A, 2008 Rev. Ed. Sing, 2008 Available: https://sso.agc.gov.sg/Act/MCA2008?ViewType=Pdf\&_=20190816120911 [Accessed 29 May 2019].

7 Legislation.Gov.UK. Mental Capacity Act, 2005 UK, 2005. Available: https://www. legislation.gov.uk/ukpga/2005/9/pdfs/ukpga_20050009_en.pdf

8 Beauchamp A, Buchbinder R, Dodson S, et al. Distribution of health literacy strengths and weaknesses across socio-demographic groups: a cross-sectional survey using the health literacy questionnaire (HLQ). BMC Public Health 2015;15(1):678.

9 Hoffmann TC, Légaré F, Simmons MB, et al. Shared decision making: what do clinicians need to know and why should they bother? Med J Aust 2014;201(1):35-9.

10 Simmons MB, Gooding PM. Spot the difference: shared decision-making and supported decision-making in mental health. Ir J Psychol Med 2017;34(4):275-86.

11 Cribb A, Entwistle VA. Shared decision making: trade-offs between narrower and broader conceptions. Health Expect 2011;14(2):210-9.

12 Makoul G, Clayman ML. An integrative model of shared decision making in medical encounters. Patient Educ Couns 2006;60(3):301-12.

13 Entwistle VA, Cribb A, Watt IS. Shared decision-making: enhancing the clinical relevance. J $R$ Soc Med 2012;105(10):416-21.

14 Joseph-Williams N, Elwyn G, Edwards A. Knowledge is not power for patients: a systematic review and thematic synthesis of patient-reported barriers and facilitators to shared decision making. Patient Educ Couns 2014;94(3):291-309.

15 Légaré F, Ratté S, Gravel K, et al. Barriers and facilitators to implementing shared decision-making in clinical practice: Update of a systematic review of health professionals' perceptions. Patient Educ Couns 2008;73(3):526-35.

16 Pathare S, Shields LS. Supported decision-making for persons with mental illness: a review. Public Health Rev 2012;34(2):15.

17 United Nations Human Rights Council. Annual report of the United nations high commissioner for human rights and reports of the office of the high commissioner and the Secretary-General, 2009. Available: https://www.un.org/disabilities/documents/ reports/ohchr/A.HRC.10.48AEV.pdf [Accessed 29 May 2019].

18 Craigie J, Bach M, Gurbai S, et al. Legal capacity, mental capacity and supported decision-making: report from a panel event. Int J Law Psychiatry 2019;62:160-8.

19 Mackenzie C. The importance of relational autonomy and capabilities for an ethics of vulnerability. In: Mackenzie C, Rogers W, Dodds S, eds. Vulnerability: new essays in ethics and feminist philosophy. New York: Oxford University Press, 2014: 33-59. 